\title{
What are federal parties promising on health?
}

\author{
Cite as: CMAJ 2019 October 21;191:E1175-6. doi: 10.1503/cmaj.1095824
}

Posted on cmajnews.com on Oct. 1, 2019

W

ith Canadians heading to the polls on Oct. 21 , health advocates and organizations have called on federal parties to put health care back on the agenda. Here's what the four major parties have promised so far.

\section{Liberals}

The Liberals have committed $\$ 6$ billion over four years to close gaps in health care. This includes "taking the next steps" to implement universal pharmacare, starting with a national drug agency to streamline the purchasing and approval of medicines and a strategy to reduce the cost of drugs for rare diseases.

They have also promised to ensure every Canadian has a family doctor, to reduce wait times, to set standards for access to mental health care, and to expand home care and palliative care.

Prime Minister Justin Trudeau has further committed to overhaul Indigenous health, promising to enact new legislation codeveloped with Indigenous governments to provide care tailored to the unique needs of different Indigenous populations. He also vowed to address critical infrastructure needs in Indigenous communities by 2030 , which would include new health care facilities.

However, the Liberals have provided few specifics about how they will achieve these promises, and the party has faced criticism for not having their promises analyzed and costed by the parliamentary budget officer. A Liberalappointed advisory council proposed a detailed plan for implementing pharmacare that would see the costs eventually rise to $\$ 15$ billion a year, but it remains to be seen if the party will commit to that plan.

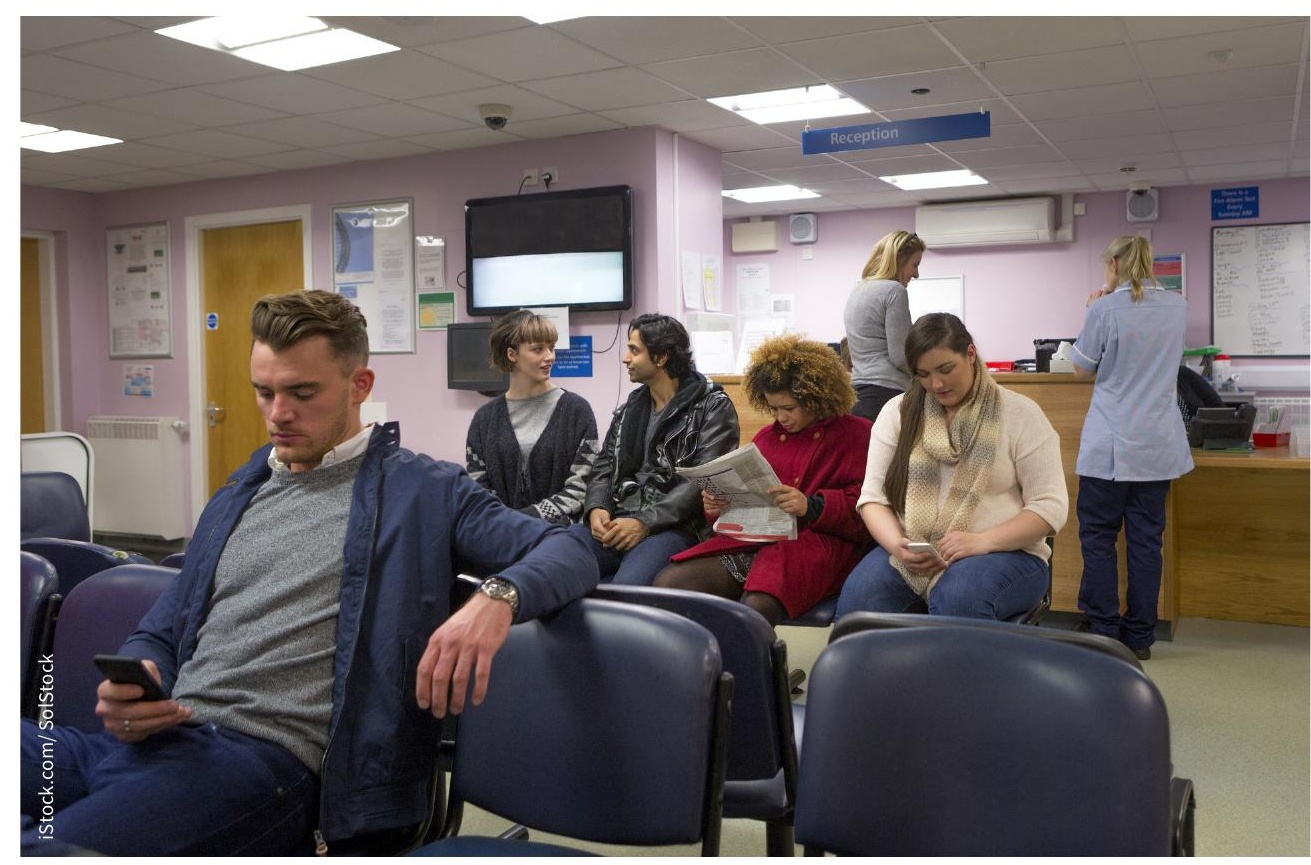

Wait times, drug coverage and dental care top some of the major parties' health platforms.

\section{Conservatives}

The Conservative platform is light on health promises. So far, they've committed to maintain the $3 \%$ increase in health transfers to the provinces that was negotiated by the Liberals.

Unlike the other three major parties, the Conservatives have dismissed the need for universal pharmacare, proposing instead to look at stop-gap measures for people who are not covered by their employer or provincial drug plans.

To tackle wait times for medical scans, they've promised $\$ 1.5$ billion in their first term to buy more diagnostic equipment.

The Conservatives will also provide $\$ 150$ back on taxes for families with children under age 18 enrolled in sports or fitness classes.

\section{New Democrats}

The New Democratic Party (NDP) was first out of the gate with their health care plan.
They're promising to implement pharmacare for all within the first year they're elected at a cost of $\$ 10$ billion annually. They also committed to work towards expanding medicare to include mental health, dental, eye and hearing coverage, and to develop national standards for home care and long-term care.

To tackle wait times, the NDP committed to identify gaps in health human resources and develop a plan to recruit and retain doctors, nurses and other health professionals. An NDP government would also work with the provinces to ensure equal access to gender-affirming surgery for transgender patients across the country.

The NDP pledged to decriminalize drugs, to declare the opioid overdose crisis a public health emergency and to seek compensation from drug companies for their role in the crisis. The party has committed to regulate natural health products 
under stand-alone legislation and to create a national autism strategy.

\section{Greens}

Like the Liberals and NDP, the Green Party has promised to create a universal pharmacare system. And like the New Democrats, they've pledged to expand medicare to include dental care for lowincome Canadians and gender-affirming health services for transgender patients. However, unlike the other parties, the
Green Party's plan comes with a much higher sticker price of $\$ 27$ billion in the first year, likely because the party had the plan costed by the parliamentary budget office.

The Greens are also proposing to reimagine the federal role in health. They've pledged to rework the health transfers to the provinces to reflect demographics, giving more money to jurisdictions with more complex and aging patient populations. They're also promising to shift the focus of Health Canada onto mental health and addiction, health promotion and disease prevention, and the health risks of climate change, and to eliminate bureaucratic delays for Indigenous patients.

Like the NDP, the Greens would decriminalize all drugs, following the model set by Portugal, and declare the opioid crisis a national emergency.

Lauren Vogel, CMAJ 